Arq. Bras. Med. Vet. Zootec., v.67, n.6, p.1616-1624, 2015

\title{
Morfologia do estômago e do duodeno da paca (Cuniculus paca Linnaeus, 1766)
}

\author{
[Morphology of the stomach and duodenum of paca (Cuniculus paca Linnaeus, 1766)] \\ M.R.F. Machado ${ }^{1}$, L.M. Leal ${ }^{2}$, T.H.C. Sasahara ${ }^{2}$, A.S. Zanetti ${ }^{1}$, C. Cruz ${ }^{3}$ \\ ${ }^{1}$ Faculdade de Ciências Agrárias e Veterinárias - Unesp - Jaboticabal, SP \\ ${ }^{2}$ Aluna de pós-graduação - Faculdade de Ciências Agrárias e Veterinárias - Unesp - Jaboticabal, SP \\ ${ }^{3}$ Centro Universitário da Fundação Educacional de Barretos - Unifeb - Barretos, SP
}

\begin{abstract}
RESUMO
Considerando a importância da paca (Cuniculus paca, Linnaeus, 1766), tanto como fonte proteica alternativa para a população quanto pela possibilidade de vir a se tornar um animal de experimentação e pela falta de informações sobre a sua anatomia, objetivou-se descrever a morfologia macroscópica e histológica do estômago e do duodeno desse roedor, reconhecendo as relações, forma e posição que esses órgãos estabelecem entre si e com outros órgãos. O estômago da paca é unicavitário, está no plano médio mais voltado para o antímero esquerdo, transversalmente, na região hipocôndrica em posição ventrocaudal, interposto entre o esôfago e o duodeno. O duodeno da paca se inicia em sequência ao estômago, segue caudalmente até o nível da quinta ou sexta vértebra lombar, na altura das quais se curva e toma direção cranial, dirigindo-se até o nível da transição entre a última vértebra torácica e a primeira vértebra lombar, onde se continua como jejuno. Histologicamente, o estômago e o duodeno da paca possuem o padrão característico da arquitetura dos órgãos ocos, apresentando as seguintes túnicas: mucosa, submucosa, muscular e serosa. Da forma que se conduziu este estudo, conclui-se que o estômago e duodeno da paca, de forma geral, possuem características morfológicas macroscópicas e histológicas semelhantes às dos animais domésticos e de outros roedores selvagens.
\end{abstract}

Palavras-chave: anatomia, roedor, selvagem

\begin{abstract}
Considering the importance of paca (Cuniculus paca, Linnaeus, 1766) as an alternative protein source for the population as well as the possibility to become an experimental model and the lack of information regarding to the anatomy of this species, the present study aims to describe the gross anatomy and the histology of the stomach and duodenum of this rodent, recognizing the relations, shape and position that these organs establish between themselves and among other organs. The paca stomach is monocavitary; it is located at the median plane, more toward the left antimere, transversally, at the hypochondriac region in a ventrocaudal position, interposed between the esophagus and duodenum. The duodenum of paca begins in sequence of the stomach, following caudally until the fifth or sixth lumbar vertebra, at this level it curves and takes the cranial direction, going until the transition level between the last thoracic vertebra and the first lumbar vertebra where it continues as jejune. Histologically, the stomach and duodenum of paca have the characteristic pattern of the hollow organs architecture, presenting the following layers: mucosa, submucosa, muscular and serous. As this study was conducted, it is possible to conclude that the stomach and duodenum of paca, in general, present gross anatomical and histological characteristics similar to the domestic animals and to the other wild rodents.
\end{abstract}

Keywords: anatomy, rodent, wild

Recebido em 25 de março de 2015

Aceito em 7 de julho de 2015

*Autor para correspondência (corresponding author)

E-mail: leonardo.vet@hotmail.com 


\section{INTRODUÇÃO}

A fauna silvestre brasileira é bastante diversificada, apresentando uma gama variável de indivíduos do grupo dos mamíferos, entre os quais os roedores vêm sendo explorados indiscriminadamente desde a época dos pioneiros da colonização agropecuária até a atualidade, pois são fonte de proteína animal. A exploração descontrolada dessas espécies agravou-se pelo avanço da fronteira agrícola, levando a uma redução significativa do nível populacional desses animais de vida livre. Pacas e cutias são citadas como importantes complementos proteicos na dieta das populações que vivem na zona rural, consequentemente, são os mamíferos de pequeno porte mais caçados nesses locais (Kleiman et al., 1980).

Além de conter uma carne com alto valor proteico, a paca possui uma boa aceitação no mercado, devido, principalmente, ao seu sabor (Gomes et al., 2013). O Brasil está entre os países com criatórios autorizados para fins comerciais (Mockrin et al., 2005).

Depois da capivara, a paca é o maior roedor das regiões tropicais. Caracteriza-se como sendo um roedor de porte médio, medindo entre 55 e $70 \mathrm{~cm}$ do focinho à ponta da cauda. Possui corpo robusto e vigoroso, com peso corpóreo entre $5 \mathrm{e}$ $10 \mathrm{~kg}$, podendo chegar até aos $14 \mathrm{~kg}$, fato este responsável pelo maior aproveitamento da carcaça, uma vez que ocorre acúmulo de músculos, especialmente nos membros pélvicos e na garupa. Alimenta-se de grande diversidade de frutas, sementes, raízes, grãos e folhagens (Matamoros e Pashov, 1982).

Por possuir características que atendem às condições necessárias a um modelo animal experimental, como tamanho adequado, ampla distribuição geográfica, adaptação a ambientes variados, nutrição variada, entre outras (Santos, 2006), acredita-se que a paca tenha grande potencial para se tornar um animal de experimentação, como sugerem Leal et al. (2014), ao utilizarem o peritônio da paca conservado como membrana biológica para corrigir defeitos da parede abdominal de outra espécie.

Assim, considerando-se a importância desse animal como fonte proteica e provável modelo experimental junto à falta de informações detalhadas do trato gastrointestinal dessa espécie na literatura, objetivou-se descrever a morfologia e a topografia macroscópica e microscópica do estômago e do duodeno da paca.

\section{MATERIAL E MÉTODOS}

Foram utilizadas 10 pacas (Cuniculus paca Linnaeus, 1766), das quais, cinco, três machos e duas fêmeas, foram destinadas aos estudos macroscópicos em peças a fresco e fixadas em solução aquosa de formoldeído a 10\%, e cinco, dois machos e três fêmeas, para a conclusão dos estudos microscópicos. Todos os animais deste experimento foram provenientes do plantel de pacas do setor de Animais Silvestres da FCAV, Unesp, Jaboticabal-SP, que é registrado no Instituto Brasileiro do Meio Ambiente e dos Recursos Naturais Renováveis - IBAMA como criatório de espécimes da fauna brasileira para fins científicos (cadastro de registro - 482508). A presente metodologia foi aprovada pela Comissão de Ética no Uso de Animais (CEUA) da Faculdade de Ciências Agrárias e Veterinárias (FCAV-Unesp), Jaboticabal-SP, de acordo com o Conselho de Experimentação animal (CONCEA), sob o número de protocolo $3.614 / 15$.

A eutanásia foi realizada mediante sedação prévia com meperidina $(3 \mathrm{mg} / \mathrm{kg})$ associada a midazolan $(1 \mathrm{mg} / \mathrm{kg})$ pela via intramuscular, anestesia geral com quetamina $(25 \mathrm{mg} / \mathrm{kg})$ e xilazina $(0,5 \mathrm{mg} / \mathrm{kg})$, também pela via intramuscular, e por fim injeção intracardíaca de cloreto de potássio $19,1 \%$, dose-efeito, até a parada cardiorrespiratória.

Após a eutanásia, os animais foram posicionados em decúbito dorsal e, por meio de incisão préretro umbilical e do rebatimento lateral das paredes abdominais, foi identificado in situ a topografia do estômago e do duodeno, além das relações e meios de sustentação desses órgãos. Em seguida esses órgãos foram individualizados e observados quanto à morfologia externa e interna do estômago. Os estômagos vazios foram pesados em balança digital semianalítica (Marte, mod. AS 1000C). Duas pacas, logo depois do óbito, foram canuladas pela artéria carótida direita para a injeção da solução de formoldeído a 10\%. Após essa injeção, as peças foram mergulhadas nessa mesma solução para 
completar o processo de fixação. Depois de fixadas, a topografia do estômago e a do duodeno foram observadas e comparadas com aquelas observadas e descritas para as peças a fresco.

Para a identificação das características histológicas do estômago e do duodeno da paca, foram coletados fragmentos das regiões inicial, próxima à cárdia; do fundo e do corpo; e pilórica do estômago, além das regiões inicial, intermediária e final do duodeno de cinco espécimes. Parte desses fragmentos foram processados para inclusão em parafina plástica e outra parte em historesina. Os fragmentos utilizados para inclusão em parafina foram previamente fixados em solução de Bouin por 24 horas e, após a inclusão, foram corados com Hematoxilina-Eosina e Tricrômico de Masson (Junqueira e Junqueira, 1983); já os fragmentos incluídos em historesina foram fixados em glutaraldeído $2,5 \%$ com tampão fostato de Sorensen $(0,1 \mathrm{M}, \mathrm{pH} 7,30)$ e após inclusão foram corados com Azul de Toluidina a 1\% Fucsina básica a 0,05\% (Behmer et al. 1976).

\section{RESULTADOS E DISCUSSÃO}

Ao analisar a situação do estômago da paca nas peças frescas e nas fixadas em paraformoldeído a $10 \%$, observou-se que esse órgão situa-se na cavidade abdominal entre o oitavo e décimo espaço intercostal nas peças fixadas e entre o oitavo e o décimo segundo espaços intercostais nas peças frescas; fato semelhante também foi observado na cobaia, no cão, gato e suíno (Mackova e Hajovsha, 1973; Sisson, 1986; Dyce et al., 2010). A variação na situação desse órgão provavelmente ocorreu devido à sua retração quando fixado na solução de formoldeído a $10 \%$, tal qual relatam Lentle et al. (1997) ao analisarem o efeito da formalina na área de superfície do rúmen de Cervus elaphus.

O estômago da paca está no plano médio mais voltado para o antímero esquerdo, transversalmente, na região do hipocôndrio, em posição ventrocaudal. Quanto à sua sintopia, está interposto entre o esôfago e o duodeno. Limita- se, em sua face parietal, com o fígado; em sua face visceral, com os intestinos delgado e grosso, e na extremidade esquerda da curvatura maior, com o baço. Comparando-se a localização e a sintopia do estômago da paca com os relatos nos animais domésticos, observamos que essas características assemelham-se às apresentadas pelos animais monogástricos (Schwarze e Schroder, 1970; Barone, 1976; Nickel et al., 1979; Dellman e Brown, 1982; Sisson, 1986; Dyce et al., 2010) (Fig. 1).

Com relação aos meios de fixação desse órgão na cavidade abdominal, constatamos, assim como no cavalo, cão, gato e suíno (Schwarze e Schroder, 1970; Sisson, 1986; Dyce et al., 2010, que o estômago da paca está fixado ao fígado por meio do omento menor e ligamento hepatogástrico; com o baço, pelo ligamento gastroesplênico; e com o diafragma, pelo ligamento gastrofrênico.

Analisando o estômago da paca isoladamente, observou-se que esse é um órgão unicavitário, possui o formato saculiforme similar a uma letra "J" invertida, como Barros Moraes et al. (2002) descrevem na capivara. Vazio, o estômago da paca apresenta em média $40 \mathrm{~g}$ de peso, quase duas vezes mais pesado que o estômago do coelho (Barone, 1976).

Assim como se verifica nos mamíferos monogástricos domésticos (Schwarze e Schroder, 1970; Sisson, 1986; Dyce et al., 2010), macroscopicamente, o estômago da paca apresenta duas curvaturas, uma maior e outra menor, nas quais não se observa a presença de tênias gástricas como Barros Moraes et al. (2002) descrevem para o estômago da capivara. Constitui-se das seguintes porções: cárdia, onde desemboca o esôfago; fundo, que, apesar de proeminente, não apresenta divertículo gástrico tal qual ocorre no suíno (Schwarze e Schroder, 1970; Sisson, 1986; Dyce et al., 2010), no porco selvagem da Indonésia (Léus et al., 1999) e na capivara (Medina, 1978; Barros Moraes et al., 2002); o corpo; e, por fim, o piloro, que desemboca no duodeno, primeira porção do intestino delgado. 

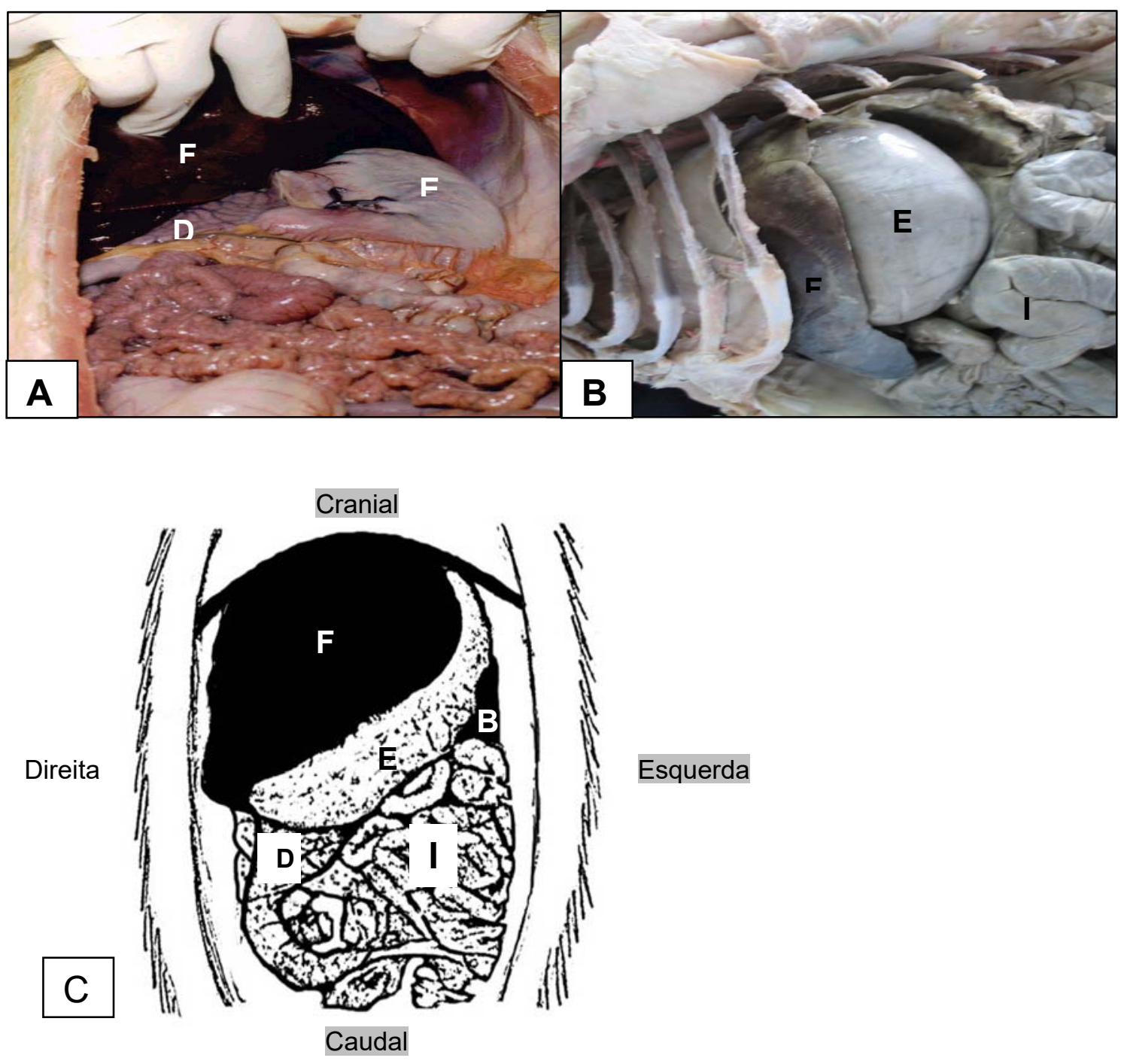

Figura 1. Fotografias e esquema da cavidade abdominal de uma paca adulta macho. Em A, paca a fresco em decúbito dorsal onde se observa o estômago (E) situado no antímero esquerdo entre o fígado (F) cranialmente e o duodeno (D) caudalmente. Em B, paca fixada em formol a 10\%, decúbito lateral direito, nota-se o estômago (A) localizado entre o oitavo e o décimo espaços intercostais e situado entre o fígado (B) cranialmente e as alças intestinais caudalmente (I). Em C, esquema ilustrando a topografia do estômago em vista ventral, observa-se: estômago (E), fígado (F), baço (B), duodeno (D) e alças intestinais (I).

Com relação à mucosa gástrica, macroscopicamente, esta apresenta variação de coloração entre as distintas porções do órgão, semelhantemente ao observado na cotia (Dasyprocta rubrata) (Garcia, 1989). Assim, a região cárdica exibe coloração rósea, cuja tonalidade se esmaece na região do fundo, tornando-se uma coloração esbranquiçada. $\mathrm{Na}$ região do corpo do estômago, observa-se uma coloração acastanhada e, por fim, a mucosa gástrica da região pilórica apresenta tonalidade rosa claro.

Histologicamente, o estômago da paca possui o padrão característico da arquitetura dos órgãos ocos, apresentando as seguintes túnicas: mucosa, submucosa, muscular e serosa, tal qual ocorre nos monogástricos domésticos (Dyce et al., 2010; Junqueira e Carneiro, 2013), no coelho (Barone, 1976), no porco selvagem da Indonésia 
(Léus et al., 1999) e nos roedores (Swallwood, 1992; Garcia e Silva, 2000; Barros Moraes et al., 2002).

Em contato com a luz do órgão, pôde-se observar na paca uma túnica mucosa que, assim como nos roedores (Medina, 1978; Garcia e Silva, 2000 e Barros Moraes et al., 2002), apresenta uma região de transição, na qual o epitélio de revestimento estratificado pavimentoso, correspondendo à região aglandular da cárdia, é substituído abruptamente pelo epitélio cilíndrico simples, constituindo a região glandular propriamente dita, composta por células de revestimento superficial secretoras de muco que se estendem por toda porção glandular desse órgão (Fig. 2). Nos animais domésticos (Schwarze e Schroder, 1970; Sisson, 1986), no coelho (Barone, 1976) e no porco selvagem da Indonésia (Léus et al., 1999), a região aglandular do estômago é maior que a observada presentemente na paca, variando em extensão entre as diferentes espécies. Assim, segundo Schwarze e Schroder, 1970, pode-se classificar o estômago da paca como sendo um estômago composto, pois parte de sua mucosa é aglandular e parte é glandular.

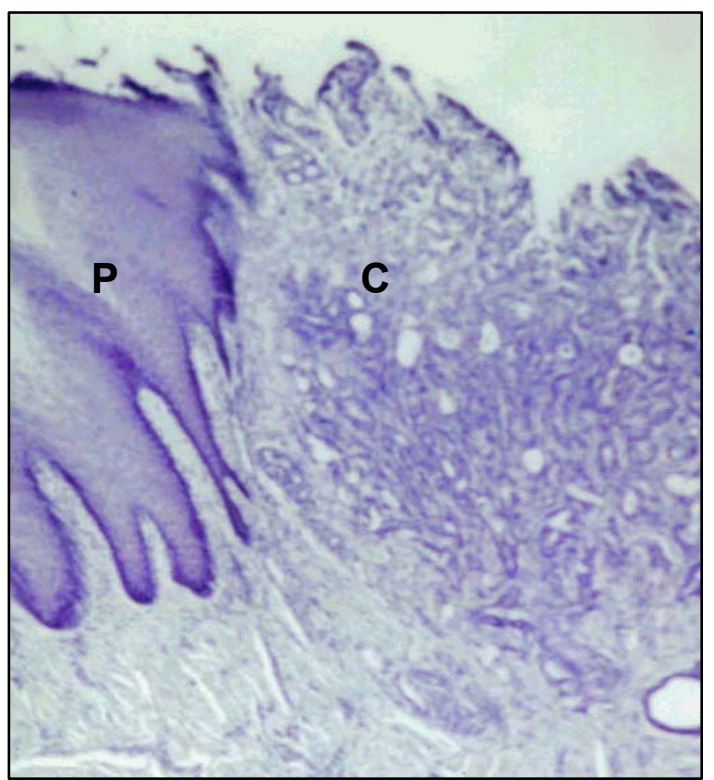

Figura 2. Fotomicrografia mostrando a transição entre o epitélio estratificado pavimentoso $(\mathrm{P})$ da porção aglandular do estômago pelo epitélio cilíndrico simples (C) referente à porção glandular do estômago da paca na região da cárdia. Parafina, Hematoxilina/Eosina. $40 \mathrm{X}$.
A região glandular do estômago da paca inicialmente apresenta as glândulas cárdicas, localizadas na lâmina própria da túnica mucosa, logo após a transição. No istmo dessas glândulas, podem-se observar células de revestimento superficial; no colo e corpo, células mucosas do colo e de reserva podem ser vistas, assim como abundantes células parietais, células estas que também são descritas na cotia e capivara (Garcia, 1989; Barros Moraes et al., 2002); além disso, algumas células principais estão presentes na base dessas glândulas, conforme as descrições de Garcia (1989) para a cotia. Isso indica que, além da produção de muco, descrita na literatura (Schwarze e Schroder, 1970; Barone, 1976; Medina, 1978; Nickel et al., 1979; Dellman e Brown, 1982; Matamoros e Pashov, 1982; Sisson, 1986; Garcia, 1989; Ghoshal e Bal, 1989; Banks, 1992; Swallwood, 1992; Garcia e Silva, 2000; Barros Moraes et al., 2002; Dyce et al., 2010; Junqueira e Carneiro, 2013), essa região, na paca, também contribui com a formação do suco gástrico e produção de pepsinogênio. Ao contrário do observado na paca, Léus et al. (1999), no porco selvagem da Indonésia, descrevem a presença das células parietais e principais apenas na região de fundo e corpo do estômago desses animais.

Com relação à muscular da mucosa do estômago da paca, esta é delgada comparando-a com a muscular da mucosa do camundongo, hamster e gerbil (Ghoshal e Bal, 1989) e ainda, sua espessura não se altera na transição aglandularglandular, ao contrário do observado na cotia por Garcia (1989).

$\mathrm{Na}$ análise histológica da região das glândulas fúndicas, compreendendo tanto a região do fundo quanto a região do corpo do estômago, a lâmina própria apresenta grande número de glândulas tubulorramificadas, tal qual ocorre no estômago dos animais domésticos (Dellman e Brown, 1982; Banks, 1992) e no do camundongo (Swalldood, 1992), predominando no colo e no corpo dessas glândulas grande número de células parietais e células mucosas do colo. Da mesma forma, na base das glândulas fúndicas, grande número de células principais podem ser visualizadas; esses achados condizem com as descrições morfológicas referentes tanto no coelho (Barone, 1976), quanto nos animais domésticos (Dellman e Brown, 1982; Sisson, 1986; Banks, 1992; Cunningham, 1999), no 
porco selvagem da Indonésia (Léus et al., 1999) e nos roedores silvestres e de laboratório (Medina, 1978; Matamoros e Pashov, 1982; Garcia, 1989; Ghoshal e Bal, 1989; Garcia e Silva, 2000 e Barros Moraes et al., 2002).

A muscular da mucosa da região das glândulas fúndicas assemelha-se à muscular da mucosa do estômago da cotia e da lapa (Agouti paca) (Garcia, 1989; Garcia e Silva, 2000) ao se apresentar mais desenvolvida que a muscular da mucosa da região das glândulas cárdicas; além disso, emite fibras de músculo liso para a lâmina própria.

A túnica mucosa da região das glândulas pilóricas do estômago da paca, diferentemente das demais regiões ora observadas, apresenta fossetas gástricas bem pronunciadas (Matamoros e Pashov, 1982; Garcia e Silva, 2000) e essas estruturas assemelham-se às observadas na cotia (Garcia, 1989) e no porco selvagem da Indonésia (Léus et al., 1999).

Devido ao fato de não termos usado sais de prata e cromo em nossas preparações histológicas, não conseguimos visualizar as células endócrinas, responsáveis pela produção de hormônios, tais como a gastrina, descrita por vários autores como produzida, principalmente, na região do antro pilórico (Garcia, 1989; Garcia e Silva, 2000; Junqueira e Carneiro, 2013), sendo responsável, dentre outras funções, pela estimulação da secreção gástrica (Cunningham, 1999). Assim, na lâmina própria dessa região, apenas células mucosas do colo, tubulares simples ramificadas, são visíveis tanto na paca (Matamoros e Pashov, 1982; Garcia e Silva, 2000) como na cotia (Garcia, 1989); no entanto, além dessas células, Barros Moraes et al. (2002) também relatam a presença de células parietais na região das glândulas pilóricas na capivara, fato não observado em nossas descrições.

Com relação à túnica submucosa, na região das glândulas cárdicas, esta é delgada, formada por tecido conjuntivo frouxo e vasos sanguíneos semelhante aos relatos de Medina (1978) e Barros Moraes et al. (2002) para a capivara e em parte aos de Ghoshal e Bal (1989), pois no hamster poucos vasos sanguíneos são visíveis. $\mathrm{Na}$ região das glândulas fúndicas, a túnica submucosa é mais evidente do que a muscular da mucosa, apresentando vasos sanguíneos e tecido conjuntivo frouxo (Medina, 1978; Matamoros e Pashov, 1982; Garcia e Silva, 2000; Barros Moraes et al., 2002). Da submucosa ramificam alguns feixes de tecido conjuntivo frouxo que podem ser observados na camada circular interna da túnica muscular. Finalmente, na região das glândulas pilóricas, a túnica submucosa é típica, ou seja, assim como nas outras regiões, apresenta vasos sanguíneos e tecido conjuntivo frouxo, além de feixes nervosos que acompanham todo o trato gastrointestinal, mas que, neste trabalho, não foi objetivo de investigação.

Sobre a túnica muscular do estômago da paca, todas as regiões apresentam a mesma constituição, pois são formadas por tecido muscular liso e encontram-se dispostas em duas camadas: uma circular interna e outra longitudinal externa (Matamoros e Pashov, 1982; Garcia e Silva, 2000); no entanto, em algumas espécies, como a capivara e o coelho, uma outra camada disposta no plano oblíquo pode ser também identificada (Medina, 1978; Ghoshal e Bal 1989).

No que diz respeito à túnica serosa, camada que recobre a maior parte do órgão externamente e que se adere firmemente à túnica muscular, exceto nas curvaturas, verificou-se que, histologicamente, esta se apresenta constituída por tecido conjuntivo frouxo, vasos sanguíneos e mesotélio, assim como nos mamífieros domésticos (Junqueira e Carneiro, 1999), nos animais de laboratório (Ghoshal e Bal, 1989; Swallwood, 1992), na cotia (Garcia, 1986) e na capivara (Barros Moraes et al., 2002).

O duodeno, primeira porção do intestino delgado, é um segmento curto quando comparado aos outros segmentos intestinais desse roedor. Em média apresenta comprimento de $33 \mathrm{~cm}$, correspondendo a $3,62 \%$ do comprimento intestinal total, fato que difere, em parte, ao descrito na paca por Garcia e Silva (2000), pois, segundo esses autores, o duodeno de uma paca adulta de $4 \mathrm{~kg}$ tem extensão de $50 \mathrm{~cm}$. No entanto, mesmo assim, ao relacionar esses dados com a literatura consultada, podemos observar que nos mamíferos domésticos, com estômago unicavitário, o comprimento do duodeno apresenta média de $25 \mathrm{~cm}$ no cavalo, porco, cão e gato (Schwarze e Schroder, 1970; Sisson, 1986; Dyce et al., 2010). 
Assim como em todos os animais domésticos (Schwarze e Schroder, 1970; Nickel et al., 1979; Sisson, 1986; Dyce et al., 2010), o duodeno da paca se inicia em sequência ao piloro, mediante um divertículo delimitado por uma prega, e segue, caudalmente, até o nível da quinta ou sexta vértebras lombares, na altura das quais se curva e toma direção cranial, dirigindo-se até o nível da transição entre a última vértebra torácica e a primeira vértebra lombar, onde se continua como jejuno.

Com relação aos meios de sustentação, em sua porção inicial, o duodeno da paca fixa-se ao fígado por meio do ligamento hepatoduodenal, e esse segmento intestinal está ligado à parede abdominal pelo mesoduodeno, como nos animais domésticos (Schwarze e Schoder,1970; Sisson, 1986; Dyce et al., 2010).

Avaliando histologicamente as regiões inicial, intermediária e final do duodeno da paca, podese observar que, entre essas regiões, não ocorrem diferenças histológicas evidentes, razão que nos leva a comentar apenas as características gerais desse órgão. Assim, o duodeno inicia-se logo após a transição gastroduodenal, onde o epitélio cilíndrico simples da região das glândulas pilóricas é substituído por projeções digitiformes, conhecidas como vilosidades. Estas, por sua vez, apresentam dois tipos celulares característicos: as células de revestimento e as células caliciformes, que apresentam forma semelhante a um cálice e que possuem a função de síntese e secreção de muco (Schwarze e Schoder, 1970; Medina, 1978; Nickel et al., 1979; Dellman e Brown, 1982; Matamoros e Pashov, 1982; Sisson, 1986; Garcia, 1989; Banks, 1992; Garcia e Silva, 2000; Junqueira e Carneiro, 2013). As células caliciformes são menos numerosas e estão localizadas entre as células de revestimento (Matamoros e Pashov, 1982; Garcia e Silva, 2000).

Em nosso estudo, a túnica mucosa do duodeno da paca apresentou algumas vilosidades mais pronunciadas do que as outras, ao contrário do observado também na paca por Garcia e Silva (2000); segundo esses autores, as vilosidades do duodeno da paca são compridas. Por outro lado, na capivara, Medina (1978) relata que as vilosidades do duodeno são curtas. Na paca, entre as vilosidades, nas regiões mais profundas dos vilos, estão as criptas de Lieberkuhn, que são glândulas simples tubulares. As células que compõem essas glândulas são as células de revestimento, células caliciformes, células de Paneth e células de reserva (Schwarze e Schoder, 1970; Medina, 1978; Nickel et al., 1979; Dellman e Brown, 1982; Matamoros e Pashov, 1982; Sisson, 1986; Garcia, 1989; Banks, 1992; Garcia e Silva, 2000; Junqueira e Carneiro, 2013). A lâmina própria é formada por tecido conjuntivo frouxo, podendo ser observados infiltrados linfocitários difusos (Matamoros e Pashov, 1982; Garcia e Silva, 2000), observados também na capivara por Medina (1989) (Fig. 3).

Na paca, a muscular da mucosa emite fibras de músculo liso para o interior das vilosidades. $\mathrm{Na}$ cotia, diferentemente do que ocorre na paca, a muscular da mucosa é interrompida em alguns trechos pelos acinos e/ou conductos excretores das glândulas de Brunner (Garcia, 1989).

As glândulas de Brunner podem ser encontradas na base da túnica mucosa do duodeno da paca. Medina (1978), para a capivara, descreve que estas se localizam na túnica submucosa. A túnica submucosa do duodeno, assim como a do estômago da paca, é formada por tecido conjuntivo frouxo e vasos sanguíneos e assemelha-se às descrições realizadas nos animais domésticos e roedores (Schwarze e Schoder, 1970; Medina, 1978; Nickel et al., 1979; Dellman e Brown, 1982; Matamoros e Pashov, 1982; Sisson, 1986; Garcia, 1989; Banks, 1992; Garcia e Silva, 2000; Junqueira e Carneiro, 2013).

Com relação à túnica muscular do duodeno da paca, podemos relatar que esta é semelhante à túnica muscular do duodeno da capivara (Medina, 1978) e da cotia (Garcia, 1989), pois está constituída por fibras musculares lisas dispostas em duas camadas: uma circular interna, espessa, e outra longitudinal externa, delgada. 


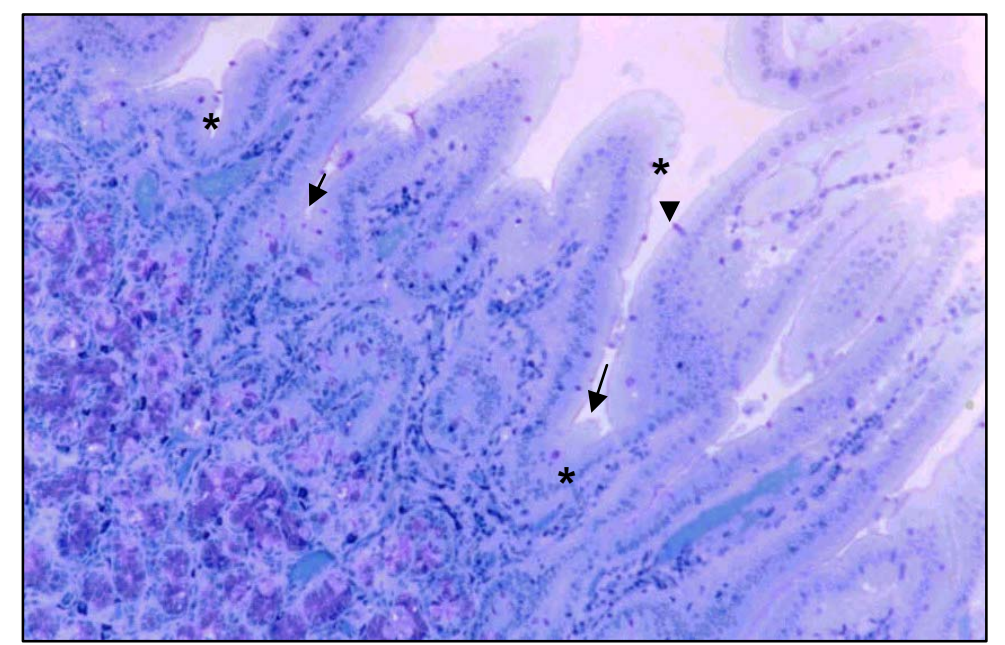

Figura 3. Fotomicrografia do duodeno de paca evidenciando as criptas de Lieberkuhn (seta) localizadas entre os vilos. Nesta fotomicrografia ainda podem ser observadas as células que compõem essas glândulas, como célula de Paneth (ponta de seta) e células caliciformes (asteriscos). Historesina, Azul de Toluidina/Fucsina básica. $100 \mathrm{X}$.

Sobre a túnica serosa, observaram-se as mesmas características observadas na túnica serosa do estômago da paca por Garcia e Silva (2000), ou seja, é formada por tecido conjuntivo associado ao mesotélio; tal constituição assemelha-se também aos relatos para a capivara (Medina, 1978) e para a cotia (Garcia, 1989).

\section{CONCLUSÃO}

Da forma como se conduziu este estudo, concluise que o estômago e o duodeno da paca, de modo geral, possuem características morfológicas macroscópicas e histológicas semelhantes às do estômago e duodeno dos animais domésticos e de outros roedores selvagens.

\section{REFERÊNCIAS}

BANKS, W.J. (Ed). Histologia veterinária aplicada. São Paulo: Manole, 1992. 658p.

BARONE, R.; PAVAUX, C.; BLIN, P.C.; CUQ, P. (Eds). Atlas d'anatomie du lapin. Paris: Masson, 1976. 224p.

BARROS MORAES, P.T; PACHECO, M.R.; SOUZA, W.M. et al. Morphological aspects of the capybara stomach (Hydrochaeris hydrochaeris): gross and microscopic structure. Anat. Histol. Embryol., v.31, p.362-366, 2002.
BEHMER, A.O.; TOLOSA, E.M.C.; FERITASNETO, A.G. (Eds). Manual de técnicas para histologia normal e patológica. São Paulo: Manole, 1976. 239p.

CUNNINGHAM, J.G. Tratado de fisiologia veterinária. Rio de Janeiro: Guanabara Koogan, 1999. 528p.

DELMAN, H.D; BROWN, E.M. (Eds). Histologia veterinária. Rio de Janeiro: Guanabara Koogan, 1982. 397p.

DYCE, K.M.; WENSING, C.J.G.; SACK, W.O. (Eds). Tratado de anatomia veterinária. Rio de Janeiro:: Elsevier, 2010. 856p.

GARCIA, G. C. Histological and histochemical studies of the digestive tract of the Agouti (Dasyprocta rubrata). Vet. Trop., v.14, p.53-83, 1989.

GARCIA, G.C.; SILVA, L. Aspectos morfológicos e histoquímicos del tubo digestivo de la Lapa (Agouti paca). Rev.Fac. Cienc. Vet., v.42, p.47-53, 2000.

GHOSHAL, N.G; BAL, H.S. Comparative morphology of the estomach of some laboratory mammals. Lab. Anim., v.23, p.21-29, 1989.

GOMES, C.; KARAM, L.B.; MACEDO R.E.F.. Atributos de qualidade da carne de paca (Agouti paca): perfil sensorial e força de cisalhamento. Arq. Bras. Med. Vet. Zootec., v.65, p.559-565, 2013. 
JUNQUEIRA, L.C.; CARNEIRO, J. Histologia básica: texto e atlas. Rio de Janeiro: Guanabara Koogan, 2013. 556p.

JUNQUEIRA, L.C.; JUNQUEIRA, L.M.M.S. Técnicas básicas de citologia e histologia. São Paulo: Santos, 1983. 123p.

KLEIMAN, D.G.; EISENBERG, J.F.; MALINIAK, E. Reproductive parameters and productivity of Caviomorph Rodents. In: EISENBERG, J.F (Ed). Vertebrate ecology in the northern neotropics. Washington: Smithsonian Institution, 1980. p.173-183.

LEAL, L.M., FERREIRA, A.R.S.; REIS, A.C.G. et al. $\mathrm{O}$ uso do peritônio de paca conservado em solução supersaturada de açúcar a $300 \%$ ou glicerina a 98\% implantados na parede abdominal de ratos. Arq. Bras. Med. Vet. Zootec., v.66, p.1383-1391, 2014.

LENTLE, R.G.; STAFFORD, K.J.; HENDERSON, I.M. The effect of formalin on rumen surface area in red deer. Anat. Histol. Embriol., v.26, p.127-130, 1997.

LEUS, K.; GOODALL, G.P.; MACDONALD, A.A. Anatomy and histology of the babirusa (Babyrousa babyrussa) stomach. Life Sci., v.322, p.1081-1092, 1999

MACKOVA, N; HAJOVSKA, B. Topografical anatomy of stomach and intestines of guineapigs. Folia Vet., v.17, p.123-131, 1973
MATAMOROS, Y; PASHOV, B. El estomago del tepeizcuinte (Cuniculus paca) su estrutura histológica y reacciones histoquímicas. Cienc. Vet., v.4, p15-20, 1982.

MEDINA, L.J.L. Contribucion al estudio histologico del tubo digestivo del Hydrochoerus hydrochaeris hydrochaeris. Rev. Fac. Cienc. Vet., v.28, p.12-41, 1978 .

MOCKRIN, M.H.; BENNET, E.L.; LABRUNA, D.T. (Eds). Wildlife farming: a viable alternative to hunting in tropical forests? New York: WCS, 2005. 32p.

NICKEL, R.; SCHUMMER, A.; SEIFERLE, E.; SACK, W.O. The viscera of the domestic mammals. In:_ (Eds.). The anatomy of the domestic animals. Berlim: Spring-Verlag, 1979. p.176-178.

SANTOS, B. F. Modelo animal. In: ANDRADE, A.; PINTO, S.C.; OLIVEIRA, R.S. (Eds). Animais de laboratório: criação e experimentação. Rio de Janeiro: FIOCRUZ, 2006. p.23-24.

SCHWARZE, E.; SCHRÖDER, L. Compendio de anatomía veterinaria. Madri: Acribia, 1970. $212 \mathrm{p}$.

SISSON, S. Aparelho digestivo. In: GETTY, R. (Ed.). Anatomia dos animais domésticos. Rio de Janeiro: Interamericana, 1986. p.105-106.

SMALLWOOD, J.E. A guided tour of veterinary anatomy: domestic ungulates and laboratory mammals. Philadelphia: Saunders Company, 1992, p. 338. 